\title{
Streamlining technical aspects to make research more efficient
}

\author{
Tam-Tri Le \\ Centre for Interdisciplinary Social Research \\ Phenikaa University, Hanoi, Vietnam \\ 2022 February 3 \\ OSF Preprints
}

This is something our mentor told us. My colleagues and I found the advice to be very useful during our research projects.

Not every researcher is a good statistician, but providing empirical evidence for scientific studies usually requires rigorous statistical analysis. Such a barrier can significantly slow down research progress, especially for young researchers who are quite inexperienced in statistics.

By employing an analytical software package with flexible yet clear step-by-step protocol, the tasks of technical analysis and validation become faster, and in a sense, more "foolproof" as well. So, research projects can progress relatively quickly without sacrificing rigorousness and integrity.

For example, our team uses the bayesvl package for Bayesian analysis [1,2].

Furthermore, with technical aspects supported by computers, researchers can spend more time and energy for deeper conceptual investigation.

\section{References}

1. La, V. P., \& Vuong, Q. H. (2019). Package 'bayesvl': Visually Learning the Graphical Structure of Bayesian Networks and Performing MCMC with 'Stan'. The Comprehensive R Archive Network (CRAN).

2. Vuong, Q.-H., La, V.-P., Nguyen, M.-H., Ho, M.-T., Tran, T., \& Ho, M.-T. (2020). Bayesian analysis for social data: A step-by-step protocol and interpretation. MethodsX, 7, 100924. https://doi.org/10.1016/j.mex.2020.100924 